\title{
Macroeconomic Determinants of Stock Market Fluctuations: The Case of Indonesia
}

\author{
Agustinus Susanto \\ University of Eastern Finland, Finland. \\ Email:_Agust.Susanto@gmail.com
}

\begin{abstract}
The study was aimed at assessing the macroeconomic determinants of stock market fluctuations in Indonesia. The quantitative data was collected through secondary sources such as World Bank. The data was collected from 1990 to 2019. The statistical testing was done through Descriptive statistics, Unit root testing and ARDL (Autoregressive Distributed Lag) model. The data was of mixed nature as it consisted of stationary and unit root. The findings revealed that the overall model was significant and in long run, there is a significant impact of macroeconomic indicators on stock prices in Indonesian market. Geographical limitation is the major issues that have restricted the collection and analysis of data. This study can also be improved by doing country comparison and industry comparison of same industries.
\end{abstract}

Keywords: Interest rate, Exchange rate, Stock market, Inflation rate, FDI, Macroeconomic indicators.

Licensed: This work is licensed under a Creative Commons Attribution 4.0 License.

Funding: This study received no specific financial support.

Competing Interests: The author declares that there are no conflicts of interests regarding the publication of this paper.

\section{Introduction}

The stock markets are a vital part of country's economy because these markets list all the public limited companies whose stocks are bought and sold by investors in this particular market. The stock markets tend to raise investment for companies benefitting the general public as well as large companies operating within the country (Pradhan, 2018). This market is most preferred by investors due to its high return and generally low to moderate risk associated with the stocks. However, the stock market is affected by the country's external factors including political environment, macroeconomic variables and technological advancements (Babajide, Isola, \& Somoye, 2016). All of them carry a significant place with regards to their impact on stock market. Nonetheless, macroeconomic indicators tend to define and signify the stock market to a great extent. There are various macroeconomic variables including country's GDP, interest rate, inflation, exchange rate, unemployment rate, FDI etc. that help in determining stock market fluctuations. According to Demir (2019) the macroeconomic variables are dynamic and change rapidly with time which in turn, specify the changes in stock market returns which is of great interest for government, investors as well as companies. Indonesia is one of the emerging markets in the world primarily famous for its tourism industry having a stable stock market and dynamic macroeconomic indicators. Since the focus of scholars recently has been on emerging economies, most of the studies have depicted the macroeconomic determinants within BRICS economies (Asongu, Akpan, \& Isihak, 2018; Syed \& Tripathi, 2020; Umar \& Sun, 2016). However, there is still little evidence related to the stock market fluctuations in Indonesia. Hence, this paper is aimed to fill the gap by focusing on the macroeconomic determinants and its impact on stock market fluctuations in Indonesia.

The study is aimed at assessing the macroeconomic determinants of stock market fluctuations in Indonesia. For this purpose, the following objectives are made;

- To examine the significance of macroeconomic dynamics on emerging economies.

- To identify and explain the macroeconomic factors associated with stock market fluctuations. 
- To analyse the impact of macroeconomic determinants on stock market fluctuations with respect to Indonesian stock market.

- To recommend investment strategies and techniques to investors for gaining higher returns with respect to macroeconomic fluctuations.

The primary research question answered through the following paper is; What is the impact of macroeconomic determinants on stock market fluctuations in Indonesian stock market? Sub-questions are defined as under;

- What is the significance of macroeconomic dynamics on emerging economies?

- What are the macroeconomic factors associated with stock market fluctuations?

- What is the impact of macroeconomic determinants on stock market fluctuations with respect to Indonesian stock market?

- What are some recommended investment strategies and techniques for investors in order to gain higher returns with respect to macroeconomic fluctuations?

\section{Literature Review}

There are numerous studies that have been conducted to analyse the important factors that tend to impact stock returns. For instance, in many textbooks and literature, one of the renowned factor models that have been discussed by many scholars is the single-factor model, which is known as the Capital Asset Pricing Model (CAPM). The rationale behind this model has been derived from the important concept associated with diversification that states that well-diversified investors should only assess systematic risks associated with a given investment (Elbannan, 2015).

In this regard, Kisman and Restiyanita (2015) have also argued that this systematic risk can be examined by looking at the sensitivity of every stock to a change within the overall market, which can be measured or assessed by looking at the Beta value. In other words, it can be stated that the market factor is the single most important factor that can be utilized to determine the stock return. Due to the simplicity of the representation associated with this model, as well as its good theoretical background, CAPM is considered as a highly renowned model which is utilized in determining the return on stock under most financial textbooks and for this reason, the model has also been used by numerous practitioners under the stock markets (Brogaard \& Detzel, 2015).

Similarly, the topics associated with the stock return and macroeconomic variables have also gained tremendous attention from different scholars that have tried to determine their relationships, which also include their impact on emerging economies. Many of these scholars have also utilized both new and traditional techniques to verify the significance of macroeconomic factors. For instance, Boako, Omane-Adjepong, and Frimpong (2016) have conducted their study about the exchange rate and stock return in which they have utilized the quantile regression to examine whether the exchange rate impact returns on stock and whether the returns on stock, in turn, influence the exchange rate. The results of their study indicated that in most of the quantiles, the exchange rate had a dramatic impact on the stock return. Nevertheless, the authors also found that the stock return had no impact on the fluctuation under the exchange rate.

Likewise, in their study, Kurov and Gu (2016) analysed the effect of monetary policy on the stock returns under both the sectorial and aggregate levels by utilizing panel and time-series regression models. For this purpose, they utilized the three-month sterling LIBOR futures contract for generating the monetary policy shock. The findings of their study indicated a substantial impact on the stock returns from both unexpected and expected changes within the interest rate. In addition to this, the authors were also able to detect and measure the structural break as the relationship between the interest rate and stock return becomes positive during the period of recession.

On the other hand, to analyse the relationship between inflation and stock return, Kurov and Gu (2016) also utilized an asymmetric test within their study. In their study, the authors were able to observe a negative relationship between these variables during the low inflation environment. However, the relationship between the variables was found to be positive under the high inflation environment. Based on this observation, they concluded this finding as an inflation protection characteristic associated with stock return.

Under the study of Rehman and Shah (2016) the lead-lagged relationship between macroeconomic variables, as well as the stock market was analysed by utilizing a vector auto-regression technique. In their study, the macroeconomic variables that were selected by the authors were mostly related to wholesales' price index, interest rate, and industrial production index. The findings of their study indicated that these macroeconomic variables had a substantial impact on the stock market. However, the authors also discovered that future economic performance was not explained by the stock market fluctuations.

These and other studies associated with macroeconomic impact on the stock markets have always remained an interesting topic for many scholars and researchers not only under the major stock markets in the developed economies but also in the stock markets of emerging economies. For European countries, the research of Antonios (2010) was based on examining the sensitivity of German stock returns to changes under the interest rates of the country. In this research, the evidence indicated that the term structure associated 
with interest rates was a highly important factor in explaining the stock returns' sensitivity in both overall and industry level in Germany. Whereas, in the study of Siliverstovs and Kholodilin (2010) variance decomposition, and vector error correction model (VECM) was used by the authors to analyse the effect of the important macroeconomic factors on Switzerland's stock market.

The results of the variance decomposition indicated that every sector was sensitive to different types of innovations under the macroeconomic variables. In this regard, Siliverstovs and Kholodilin (2010) further argued that this information was highly useful for the allocation of strategic assets in different sectors to control the risks associated with macroeconomic variables. Likewise, Artikis and Nifora (2012) in their research was found to study the interaction among the stock market and macroeconomic variables in Greece. The findings of their research indicated that the movement under the stock market was not the leading indicator associated with the fluctuations in macroeconomic variables while the macroeconomic dynamics were found to partially explain the fluctuations within the stock market. Korhonen and Peresetsky (2016) also used the EGARCH model to assess the impact of macroeconomic variables on the Russian stock exchange market under which they discovered that the stock market was heavily dependent on both the US Dollar exchange rate, as well as oil prices.

While the study of Ozturk and Yilmaz (2015) was based on examining the impact of macroeconomic factors and dynamics on the stock return under the stock exchange market of Istanbul, Turkey. In this study, seven important macroeconomic factors were identified by the authors which were related to money market interest rate, consumer price index, industrial production index, gold price, oil price, money supply, as well as foreign exchange rate. The results of this study indicated that the money supply had a significant positive impact on the returns of stock, while the variables related to the exchange rate, oil price, production index, and interest rate had a significant negative impact on the stock returns.

Besides, the above-stated countries, several studies describing the relationship between stock market fluctuations and macroeconomic determinants are also popular under the emerging Asian countries. For instance, the study of Yang, Kim, Kim, and Ryu (2018) under which the authors were found to utilize Fama's proxy hypothesis framework can be considered as an example where the relationship between the real activities, inflation, and real stock return was assessed with respect to the Korean market. The findings of their research highlighted a negative relationship between the real stock return and inflation rate in the Korean stock exchange market. This negative relationship was described by the authors as driven from the inflationary pressure to the future potential earnings of the listed companies, as well as a higher nominal discount rate.

Similarly, the relationship between the macroeconomic variables and the stock market in Singapore has also been analysed by Leong and Hui (2014) who were able to discover the presence of co-integration between every important macroeconomic variable under their study and market index. While examining the sectorial level, the authors were also able to find a co-integration between all macroeconomic variables and the property sector of the country. Nevertheless, while analysing the finance sectors, the authors were not able to found a significant relationship between real economic activities and money supply and for the hotel sector, an insignificant relationship was noted by the authors between the money supply and interest rates of the country.

\section{Methodology}

As stated earlier, the study is aimed at assessing the impact of macroeconomic determinants on stock market fluctuations which is based on numbers; hence, a positivist approach has been used to conduct the study. The reason why this research philosophy has been selected to conduct this study is that it adheres to the view that only factual or objective knowledge which is attained through observation (i.e., senses), as well as through measurement, can be considered as trustworthy. Due to this reason, in most positivism studies, the researcher's role is restricted to collecting and interpreting the data in an objective way (Ryan, 2018). Therefore, by using this philosophy, objective inferences have been made by analysing the collected data in order to test the hypotheses and accomplish the objectives of this research.

Similarly, as quantitative analysis has been made in this research, the quantitative research methodology has also been used to provide appropriate inferences related to the relationship between the study's key variables (i.e., stock market fluctuations and macroeconomic determinants). This research methodology has further assisted to increase both the accuracy and objectivity of the inferences and conclusions that have been made to describe the relationship between stock market fluctuations and macroeconomic determinants of Indonesia (Bryman, 2017).

\subsection{Unit Root Testing}

Under this research, the unit root testing method has been used to determine whether the analysed data associated with the key variables of this study is stationary or not. After using this technique, the autoregressive distributed lag (ARDL) analysis has also been carry out in the research to evaluate the impact of macroeconomic determinants on the stock returns. Moreover, to conduct these time series analyses, the primary data that has been gathered for this research has focused on analysing the changes under the variables between 1990 and 2019 . 
The processing of a time series, by considering the findings of Beare (2018) typically comprise certain assumptions and limitations that are needed to be followed while predicting and analysing different time series under given research. Thus, it is highly essential to explain how certain criteria and assumptions are important to consider while conducting an econometric assessment that has also been carried out in this research.

In addition to this, the quantitative data for this study has been collected by accessing the IDX Composite index of the Indonesian Stock Exchange (IDX) which can also be classified as secondary data. Therefore, it can be stated that for this study, the desk research method has been employed. As most stock markets in different countries are impacted by different macroeconomic determinants (which was also evident under the critical analysis of the literature review), this research has specifically focused on determining the impact of macroeconomic variables associated with the interest rate, inflation rate, and exchange rate of Indonesia on the stock market returns or returns on investment that are attained by the stockholders in the country.

Similarly, it has also analysed the impact of foreign direct investments (FDI) that the local investors or stockholders in Indonesia can make in other countries to protect themselves from the risk associated with capital losses that they are compelled to face during high fluctuations under the stock exchange market in their home country (i.e., Indonesia). By considering these variables and the above literature review, the conceptual framework of this research has been provided below.

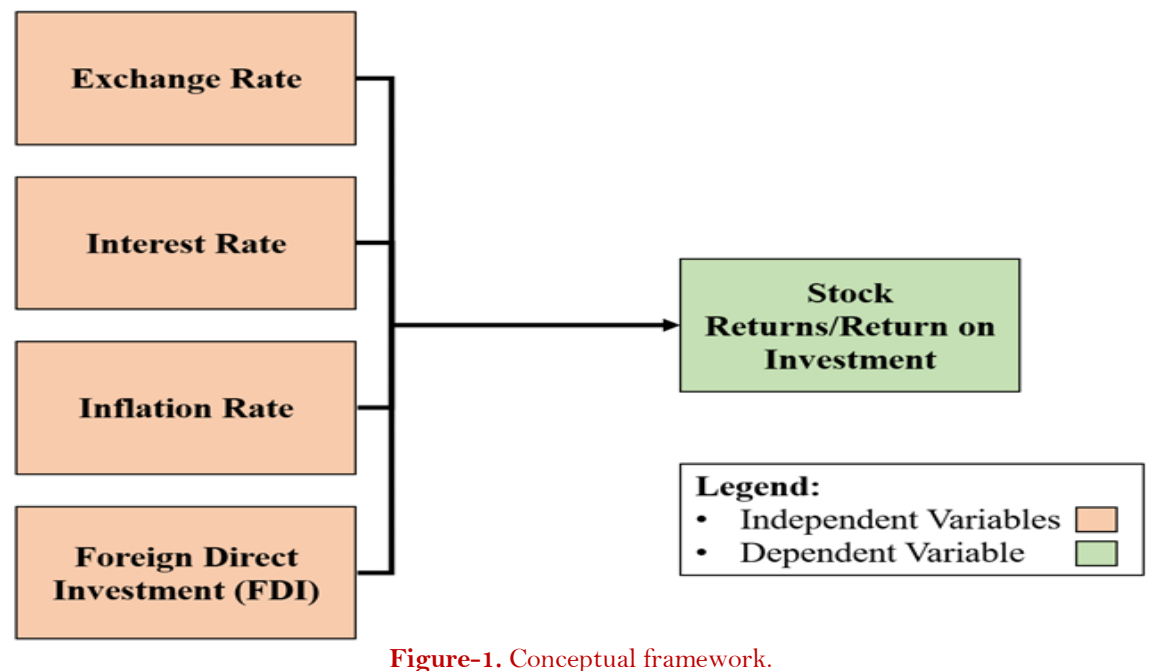

The relationship between the explained and explanatory variables of this research (as highlighted by the above conceptual framework) can also be understood by using the following empirical equation:

Where:

$$
S P_{t=\alpha}+\beta_{t}\left(I R_{t}\right)+\beta_{2}\left(I_{t}\right)+\beta_{s}\left(X E_{t}\right)+\beta_{t}\left(F D I_{t}\right)+\varepsilon
$$

- SP: Stock Price.

- IR: Inflation Rate.

- I: Interest Rate.

- FDI: Foreign Direct Investment.

In this research, Autoregressive Distributed Lag, as well as Augmented Dickey-Fuller have also been implemented. The detailed explanations of these methods have been provided below:

\subsection{Augmented Dickey-Fuller (ADF)}

As stated earlier, this research has analysed the impact of macroeconomic determinants on the stock returns (i.e., the return on investment) of the investors in Indonesia. Thus, to understand the current research phenomenon, the time series data associated with the macroeconomic determinants (i.e., inflation rate, interest rate, exchange rate, and FDI), as well as stock returns in Indonesia were collected from 1990 to 2019. Nevertheless, while using time-series data, researchers are often required to follow certain assumptions. Thus, the fundamental assumption criteria which have been used in this research have followed the stationarity of time-series. This stationarity of time-series data can be evaluated by using the ADF technique which has also been utilized in this research. This ADF technique typically assists in forming the basis of the assumption that is used to propose the null hypothesis of time-series data that also requires the use of unit-roots (Paparoditis \& Politis, 2018).

In this regard, it can be stated that the rejection or acceptance of the null hypothesis helps in determining whether time-series comprises unit-roots. Upon confirming the presence of unit roots under the time series, appropriate inferences are made to conclude that the data is stationary, and vice versa. The ADF approach can also be explained by using the following mathematical model: 


$$
\Delta \mathrm{a}_{t}=\lambda_{0}+\forall+\lambda_{2} \mathrm{a}_{t-1}+\sum_{i=1}^{n} m x 1 \Delta \mathrm{a}_{t-1}+\gamma
$$

As indicated by the above-provided equation, $\Delta$ can be described as the difference operator. On the other hand, $\gamma$ in the equation indicates the random error of stationary. Further, $\mathrm{a}_{t}$ highlights non-stationary timeseries data.

\subsection{Autoregressive Distributed Lag (ARDL)}

The statistical technique associated with ARDL is also commonly utilized to determine the long-term associations while conducting the econometric assessment under given research. By considering the findings of Nkoro and Uko (2016) this approach is commonly utilized to determine the long-term relationship or association between two quantitative variables. Moreover, this technique is also frequently used to form the basis of the analysis by using an iterative approach under which the time-series' marginal log is maximized. The below-provided equation highlights the standard log-linear function that is generally used under this approach:

$$
G_{t}=\beta+\alpha \mathrm{ER}_{t}++\gamma_{t}
$$

In the above-provided equation, $\mathrm{ROI}_{\mathrm{t}}$ describes the $\log$ of return on investment, while the $Y$ in the equation represents the error terms and $\alpha$ denotes the parameter estimate.

$$
\Delta G_{t}=\beta 2+\sum_{i=1}^{m 2} \nabla_{2 i} \Delta G_{t-i}+\sum_{j=0}^{m 2} \alpha_{2 j} \Delta F O P_{z-j}+\gamma_{2 t}
$$

Hence, $Y$ represents significant coefficient.

\section{Results}

For the purpose of analysing the collected data from the World Bank's website, the results have been presented below. Along with the results, the discussion and conclusion is also given related to the research topic and the findings. This section has outlined descriptive statistics of the data, evaluation of unit root as the study has used time series data and assessment of relationship through ARDL approach.

\subsection{Descriptive Statistics}

This section determines the average of exchange rate, interest rate, inflation rate and FDI along the period of 1990 to 2019. The table of descriptive statistics below also show minimum and maximum values through which the range is computed. On the other hand, standard deviation has been used to calculate the deviation as well.

The results in the below table are showing that average exchange rate value in the period from 1990 to 2019 has been $\$ 8,236.03$, the average value of interest rate has been $548.3 \%$ in Indonesia and the average inflation rate has been $925.0 \%$. The average value of FDI had been $\$ 8,120,000,000$. On the other hand, the deviation in exchange rate had been $\$ 4,078.24$, the deviation in interest had been $744.7 \%$ and the deviation in

\begin{tabular}{|c|c|c|c|c|}
\hline Variable & Mean & Std. & Min & Max \\
\hline Exchange Rate & $\$ 8,236.03$ & $\$ 4,079.24$ & $\$ 1,842.81$ & $\$ 14,236.94$ \\
\hline Interest Rate & $548.3 \%$ & $744.7 \%$ & $-2460.0 \%$ & $1560.7 \%$ \\
\hline Inflation Rate & $925.0 \%$ & $998.4 \%$ & $303.1 \%$ & $5845.1 \%$ \\
\hline FDI & $\$ 8,120,000,000.00$ & $\$ 9,240,000,000.00$ & $-\$ 4,550,000,000.00$ & $\$ 25,100,000,000.00$ \\
\hline Stock Price Volatility & 179.0 & 146.4 & 15.0 & 533.1 \\
\hline Stock Return Volatility & $6.18 \%$ & $3.57 \%$ & $0.00 \%$ & $17.25 \%$ \\
\hline
\end{tabular}
inflation rate was $998.4 \%$. The average values of stock price and stock returns are 179 and $6.18 \%$ respectively.

Table-1. Descriptive Statistics.

\subsection{ADF Testing to Evaluate Unit Root}

As discussed in the initial section that ADF testing was carried out since the data is was time series in nature. It is assumed that non-stationary characteristics are present in null hypothesis of the study. The results have been presented below in Table 2 and are computed through E-Views. As per the details of the results, the t-statistics of exchange rate is -1.59 with $\mathrm{P}$ value of 0.4886 . This implies that $\mathrm{P}$ value is greater than all the standard values such as $5 \%, 1 \%$ or $10 \%$. Hence it indicates that exchange rate has a unit root. Similarly, the t-statistics of interest rate is -5.448 with 0.0 as the P-value. This means that the data was stationary and there was no unit root in interest root as the $\mathrm{P}$ value was $0.000(\mathrm{p}$-value $<0.05)$ and the null hypothesis was negated in this case. The t-statistics of inflation rate was -4.285 with 0.0005 as p-value. Since the p-value is less than the threshold values hence, there is no unit root in inflation rate too.

Moreover, the t-statistics of FSDI was -8.347 with 0.00 as the $p$ value hence it also means that due to stationarity in data, there is no unit root. In case of stock price and stock return, the t-statistics was -..183 and - 
3.124 respectively whereas, the p-values were 0.3658 and 0.0248 . Overall, mixed nature of the data series can be observed from the results obtained hence, the methodology adopted later is decided in accordance with the nature of the data.

\begin{tabular}{l|c|c}
\multicolumn{3}{c}{ Table-2. UNIT root testing. } \\
\hline Variable & Test Statistics & P-Value \\
\hline Exchange Rate & -1.59 & 0.4886 \\
\hline Interest Rate & -5.448 & 0 \\
\hline Inflation Rate & -4.285 & 0.0005 \\
\hline FDI & -8.347 & 0 \\
\hline Stock Price Volatility & -1.83 & 0.3658 \\
\hline Stock Return Volatility & -3.124 & 0.0248 \\
\hline
\end{tabular}

\subsection{Bounds Testing}

Bounds testing are another way or approach of co-integration where variables are bound together in the long run period. This method has several benefits as it is new and helps in determining whether there will be any association between the variables in future or in long run or not. This tests is used irrespective of the fact whether the series of data is mixed or not. The values shown below of t-statistics and f-statistics alongside the p-values indicate the results.

Table-3. Bound Values.

\begin{tabular}{c|c|c|c|c|c|c|c|c}
\hline & \multicolumn{2}{|c|}{$\mathbf{1 0} \%$} & \multicolumn{2}{c|}{$\mathbf{5 \%}$} & \multicolumn{2}{c|}{$\mathbf{1 \%}$} & \multicolumn{2}{c}{ P-value } \\
\hline & $\mathbf{I}(\mathbf{0})$ & $\mathbf{I}(\mathbf{1})$ & $\mathbf{I}(\mathbf{0})$ & $\mathbf{I}(\mathbf{1})$ & $\mathbf{I}(\mathbf{0})$ & $\mathbf{I}(\mathbf{1})$ & $\mathbf{I}(\mathbf{0})$ & $\mathbf{I}(\mathbf{1})$ \\
\hline $\mathbf{F}$ & 2.828 & 4.353 & 3.582 & 5.396 & 5.603 & 8.152 & 0.016 & 0.065 \\
\hline $\mathbf{t}$ & -0.2478 & -3.622 & -2.9 & -4.133 & -3.805 & -5.235 & 0.004 & 0.042 \\
\hline
\end{tabular}

\subsection{Autoregressive Distributed Lag Model}

From the results obtained in previous section (ADF testing), it was assessed that the nature of the data is mixed where some variables have unit root whereas some are stationary hence, the model selected for analysis after considering the nature of data is ARDL Model. The results are presented below in Table 4 that shows the t-statistics and p-values obtained. Also, it has the optimal Lag order which was selected by E-Views automatically. To ensure that the errors of data are fixed so, HAC error was used to strengthen the assessment between the independent and dependent variables. For the purpose of selecting the optimal model, in the first lag, stock return volatility had significant result $(\mathrm{B}=-2.335$ with $\mathrm{P}$-value of 0.001$)$. Furthermore, the interest rate had also significant result in first lag $(B=-0.00511$ with $\mathrm{P}$ value of 0.00$)$. However, contrary to these results, inflation rate had insignificant results in first lag because of the values obtained less than the threshold value $(B=0.00038$ and $P$-value of 0.651$)$. The first lag of FDI shows it has significant results $(B=-$ 0.00176 with P-value of 0.015). Similarly, all other results shown below are also of same nature and they indicate in second lag that significant results were not obtained.

Table-4. ARDL model of the research short run.

\begin{tabular}{|c|c|c|c|c|c|c|}
\hline & Coef. & Std. Err. & $\mathrm{t}$ & $\mathbf{P}>|\mathbf{t}|$ & \multicolumn{2}{|c|}{ [95\% Conf. Interval] } \\
\hline \multicolumn{7}{|c|}{ 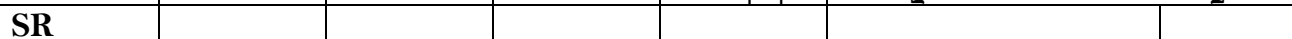 } \\
\hline \multicolumn{7}{|c|}{ Stock Return Volatility } \\
\hline LD. & 0.96287 & 0.36002 & 2.67 & 0.019 & 0.18509 & 1.74066 \\
\hline L2D. & 0.31308 & 0.26306 & 1.19 & 0.255 & -0.2552 & 0.88138 \\
\hline \multicolumn{7}{|c|}{ Interest rate } \\
\hline $\mathrm{D} 1$. & -0.0064 & 0.00187 & -3.4 & 0.005 & -0.0104 & -0.0023 \\
\hline LD. & 0.00494 & 0.00174 & 2.85 & 0.014 & 0.00119 & 0.00869 \\
\hline L2D. & 0.00487 & 0.00144 & 3.37 & 0.005 & 0.00175 & 0.00798 \\
\hline L3D. & 0.00358 & 0.00101 & 3.56 & 0.004 & 0.00141 & 0.00576 \\
\hline \multicolumn{7}{|c|}{ Inflation rate } \\
\hline D1. & -0.0015 & 0.00134 & -1.15 & 0.269 & -0.0044 & 0.00135 \\
\hline \multicolumn{7}{|l|}{ LFDI } \\
\hline D1. & -0.0041 & 0.00201 & -2.04 & 0.062 & -0.0085 & 0.00025 \\
\hline _cons & 0.80285 & 0.1985 & 4.04 & 0.001 & 0.37401 & 1.23168 \\
\hline
\end{tabular}

Overall it can be concluded that since the aim of the study was to determine the impact of macroeconomic determinants on stock market fluctuations with respect to Indonesian stock market therefore, it can be concluded that since the $\mathrm{P}$-value is less than the threshold values such $(\mathrm{p}=0.019)$ therefore, statistical relationship to some extent can be observed. Based on this assertion, it can be found that macroeconomic indicators (inflation rate, exchange rate, FDI and can have impact over stock prices or stock returns considering the external factors remain the same. The Table 4 below was also divided into long run and short 
run so that the association or the relationship between the macroeconomic indicators and stock price return can be assessed. It also depends on the lag values. In the long run period, FDI (p-value at 0.015) and stock return volatility (p-value at 0.001 ) have significant results. On the contrary, in the short run period, lag of interest rate (p-value at 0.005). Therefore, it depends on the lag values and the short run and the long run period.

Table-5. ARDL model of the research long run.

\begin{tabular}{l|c|c|c|c|c|c}
\hline & Coef. & Std. Err. & $\mathbf{t}$ & $\mathbf{P}>\mid \mathbf{t}$ & \multicolumn{2}{c}{$[\mathbf{9 5 \%}$ Conf. Interval] } \\
\hline LR & & & & & & \\
\hline Stock Return Volatility & -2.3351 & 0.54827 & -4.26 & 0.001 & -3.5196 & -1.1507 \\
\hline LER & -0.0274 & 0.00395 & -6.94 & 0 & -0.0359 & -0.0189 \\
\hline Interest rate & -0.0051 & 0.00073 & -7.03 & 0 & -0.0067 & -0.0035 \\
\hline Inflation rate & 0.00038 & 0.00082 & 0.46 & 0.651 & -0.0014 & 0.00216 \\
\hline LFDI & -0.0018 & 0.00063 & -2.81 & 0.015 & -0.0031 & -0.0004 \\
\hline
\end{tabular}

The results of the study can be validated from another study conducted in similar domain by Demir (2019) that has revealed that economic growth, portfolio investments and FDI help in raising the stock market whereas, interest rate and oil prices negatively impact it. ARDL approach was adopted in this study and it was suggested that stock exchange should increase capital inflow and their investments. The stationarity of the variables was also tested through $\mathrm{ADF}$, and unit root testing that were developed by Dickey and Fuller (1979) and Phillips and Perron (1988).

\subsection{Hypothesis Assessment Summary}

The primary assessment and overall evaluation has revealed that the overall model is significant. There is a more strong association during the long run as compared to short run. It was also found that stock prices is significantly dependent on its lagged values. Based on the results obtained, it can be stated that the proposed hypothesis has been accepted.

\section{Discussion}

Several studies are conducted in similar domain which has analysed the impact of macroeconomic indicators with stock prices. The following study used the case of Indonesian market so that in-depth data can be collected and evaluated. The data was obtained from 1990 to 2019 from World Bank. The data was also assumed to be mixed because some of the variables were stationary whereas, some had unit root. This was the major rationale behind opting for ARDL model testing as the data was of mixed nature. Furthermore, it had been found from the previous studies that risks is one of the essential element that is present and every stock market has to face this. Kisman and Restiyanita (2015) determined in their study that market factor can be used for finding the impact on stock returns though the stock prices fluctuate on daily basis due to various external factors. Similarly, CAPM model is found to be significant in case of assessing stock returns with other variables. The macroeconomic indicators such as inflation rate, exchange rate and FDI are affected by many changes in the local economy such as increase in prices, government international deals or any political shocks or inflow of more investments and dollar price fluctuations. Even oil has a significant part in changing the stock prices on daily basis.

In addition to this, it was also found that there is a strong interrelationship between financial development and economic growth due to which the macroeconomic variables such as interest rate and exchange rate are influenced too. Despite of the studies conducted in this domain, Indonesian stock market was selected because the current studies are conducted on large economies such as China and USA. There is limited data available regarding Indonesian market and the fluctuations observed in stock prices. Thus, based on the results obtained above it is evident that in short and in long run, the macroeconomic variables behave differently and the results obtained are also different. In the short run, there might be no impact but in the long run, there is a significant impact.

\section{Conclusion}

In order to conclude the research article, it can be stated that the independent variables selected in this study were interest rate, inflation rate, exchange rate and FDI whereas, the dependent variable was stock return. Conclusively, the overall model was found to be significant and in the long run, there is impact of macroeconomic indicators on stock prices in the Indonesian market. The government needs to design policies for controlling inflation rate and exchange rate fluctuations. The government should encourage foreign investors so that inflow of FDI can increase and benefit the economy and growth. Precisely, it is advised that government should focus on creating a strong mechanism that helps in increasing investment and more exports should be exported through local production. This may lead towards significant impact on stock market in short run period. 


\section{Limitations of Study and Future Directions}

The following research article was based on Indonesian market hence, it entails that geographical limitation is the major issues that has restricted the collection and analysis of data. The results of the study cannot be generalized to other developing or developed countries. In order to improvise the results in future, the data can be collected from Malaysia and Thailand. In terms of the macroeconomic indicators, the future papers can include more indicators and assess them in short run and long run period. Moreover, this study can also be improved by doing country comparison and industry comparison of same industries. The researcher can use the data of different countries along with different indicators and find the impact on GDP and GNP too.

\section{References}

Antonios, A. (2010). Stock market and economic growth: An empirical analysis for Germany. Business and Economics Journal, 1-12.

Artikis, P. G., \& Nifora, G. (2012). Capital structure, macroeconomic variables \& stock returns. Evidence from Greece. International Advances in Economic Research, 18(1), 87-101.Available at: https://doi.org/10.1007/s11294-0119334-Z.

Asongu, S., Akpan, U. S., \& Isihak, S. R. (2018). Determinants of foreign direct investment in fast-growing economies: Evidence from the BRICS and MINT countries. Financial Innovation, 4(1), 26.

Babajide, A., Isola, L., \& Somoye, R. O. (2016). Stock market response to economic growth and interest rate volatility: Evidence from Nigeria. International Journal of Economics and Financial Issues, 6(1), 354-360.

Beare, B. K. (2018). Unit root testing with unstable volatility. Journal of Time Series Analysis, 39(6), 816-835.

Boako, G., Omane-Adjepong, M., \& Frimpong, J. M. (2016). Stock returns and exchange rate nexus in Ghana: AB ayesian quantile regression approach. South African Journal of Economics, 84(1), 149-179.Available at: https://doi.org/10.1111/saje.12096.

Brogaard, J., \& Detzel, A. (2015). The asset-pricing implications of government economic policy uncertainty. Management Science, 61(1), 3-18.Available at: https://doi.org/10.1287/mnsc.2014.2044.

Bryman, A. (2017). Quantitative and qualitative research: further reflections on their integration. In Mixing methods: Qualitative and quantitative research (pp. 57-78): Routledge.

Demir, C. (2019). Macroeconomic determinants of stock market fluctuations: The case of BIST-100. Economies, 7(1), 114.Available at: https://doi.org/10.3390/economies7010008.

Dickey, D. A., \& Fuller, W. A. (1979). Distribution of the estimators for autoregressive time series with a unit root. Journal of the American statistical association, 74(366a), 427-431.Available at: https://doi.org/10.1080/01621459.1979.10482531.

Elbannan, M. A. (2015). The capital asset pricing model: an overview of the theory. International Journal of Economics and Finance, 7(1), 216-228.

Kisman, Z., \& Restiyanita, S. (2015). M. The validity of capital asset pricing model (CAPM) and Arbitrage Pricing Theory (APT) in predicting the return of stocks in Indonesia Stock Exchange. American Journal of Economics, Finance and Management, 1(3), 184-189.

Korhonen, I., \& Peresetsky, A. (2016). What influences stock market behavior in Russia and other emerging countries? Emerging Markets Finance and Trade, 52(5), 1210-1225.Available at: https://doi.org/10.1080/1540496x.2015.1037200.

Kurov, A., \& Gu, C. (2016). Monetary policy and stock prices: Does the "Fed Put" work when it is most needed? Journal of Futures Markets, 36(12), 1210-1230.Available at: https://doi.org/10.1002/fut.21790.

Leong, C. C., \& Hui, T. K. (2014). Macroeconomic and non-macroeconomic variables linking to Singapore hotel stock returns. In Advances in hospitality and leisure: Emerald Group Publishing Limited.

Nkoro, E., \& Uko, A. K. (2016). Autoregressive Distributed Lag (ARDL) cointegration technique: Application and interpretation. Journal of Statistical and Econometric Methods, 5(4), 63-91.

Ozturk, H., \& Yilmaz, A. A. (2015). Leverage and stock returns: Evidence from Istanbul stock exchange. Accounting and Finance Research, 4(4), 140

Paparoditis, E., \& Politis, D. N. (2018). The asymptotic size and power of the augmented Dickey-Fuller test for a unit root. Econometric Reviews, 37(9), 955-973.Available at: https://doi.org/10.1080/00927872.2016.1178887.

Phillips, P. C., \& Perron, P. (1988). Testing for a unit root in time series regression. Biometrika, 75(2), 335-346.Available at: https://doi.org/10.1093/biomet/75.2.335.

Pradhan, R. P. (2018). Development of stock market and economic growth: The G-20 evidence. Eurasian Economic Revierw, 8(2), 161-181.Available at: https://doi.org/10.1016/j.econmod.2017.07.005.

Rehman, A., \& Shah, A. (2016). Lead-lag relationship and directional asymmetry in stock returns of small and large portfolios: Evidence from the Karachi Stock Exchange. IBA Business Review, 11(2).

Ryan, G. (2018). Introduction to positivism, interpretivism and critical theory. Nurse Researcher, 25(4), 41-49.Available at: https://doi.org/10.7748/nr.2018.e1466.

Siliverstovs, B., \& Kholodilin, K. A. (2010). Assessing the real-time informational content of macroeconomic data releases for now-/forecasting GDP: Evidence for Switzerland.

Syed, A., \& Tripathi, R. (2020). Nonperforming Loans in BRICS Nations: Determinants and Macroeconomic Impact. Available at SSRN 3528097.

Umar, M., \& Sun, G. (2016). Determinants of different types of bank liquidity: Evidence from BRICS countries. China Finance Review International, 6(4), 380-403.Available at: https://doi.org/10.1 108/cfri-07-2015-0113.

Yang, E., Kim, S. H., Kim, M. H., \& Ryu, D. (2018). Macroeconomic shocks and stock market returns: The case of Korea. Applied Economics, 50(7), 757-773.Available at: https://doi.org/10.1080/00036846.2017.1340574. 